Tatiana Bukowitz

\title{
MISTIFICAÇÃO DO REAL OU TOTALIDADE CONCRETA: O QUE DIZEM OS DADOS SOBRE A PRÁTICA PEDAGÓGICA DE DOCENTES DA SOCIOLOGIA DA ESCOLA BÁSICA? ${ }^{1}$
}

Tatiana Bukowitz ${ }^{2}$

\section{RESUMO}

Como se caracterizam a realidade pedagógica e a estrutura de trabalho profissional de docentes de sociologia/ciências sociais do ensino médio? Qual o alcance das ações pedagógicas desses docentes diante das condições objetivas e subjetivas que circunscrevem o cotidiano de suas práticas educacionais? Qual a interferência dessa estrutura de trabalho nas demais esferas da vida dessas pessoas que assumem a docência de sociologia na escola básica como profissão? Estas três questões nortearam o percurso investigativo que culminou na tese "Sociologia como (in)disciplina escolar: desafios da prática docente" (defendida em junho de 2015 no PPFH - UERJ, Programa de Pós-Graduação de Políticas Públicas e Formação Humana da Universidade do Estado do Rio de Janeiro). Para responder essas perguntas, realizou-se pesquisa de campo para captar dados que permitissem a caracterização da realidade de vida desses profissionais. Este trabalho apresenta, portanto, uma síntese analítica dos dados desta pesquisa de campo. As entrevistas realizadas neste percurso de investigação foram feitas em duas etapas. Na primeira, utilizou-se questionário semiestruturado com um total de 61 questões (mesclando questões objetivas com questões abertas), aplicado presencialmente a 10 docentes do Rio de Janeiro (região metropolitana da capital do Estado). A segunda etapa foi realizada com outros 10 docentes ( 6 do Rio de Janeiro e 4 de outros estados), empregando questionário semiestruturado, também mesclando questões objetivas com questões abertas, porém com um número reduzido de questões, uma vez que visávamos conferir, especialmente, os dados documentados relativos à remuneração total mensal advinda da docência em sociologia por escola e também uma confirmação sobre a média do quantitativo de turmas e estudantes ao cago de cada docente, em cada escola dessa região. Os integrantes desse segundo grupo de entrevistados forneceram cópias dos contracheques de suas atividades como profissionais docentes de sociologia, atestando de modo oficial os dados referentes aos salários por eles declarados. Os dados objetivos e os elementos subjetivos

\footnotetext{
${ }^{1}$ Artigo apresentado nos Anais Evento Conjugado ENCS - O Ensino de Ciências Sociais em tempos de exceção: desafios e perspectivas, de 7 a 9 de novembro de 2016, na Universidade Federal do Rio Grande do Norte.

2 Doutora em Políticas Públicas e Formação Humana pela Universidade do Estado do Rio de Janeiro (UERJ). Professora do Departamento de Sociologia do Colégio Pedro II do Rio de Janeiro.

E-mail: tatikawaii@hotmail.com
} 


\section{INTER-LEGERE}

MISTIFICAÇÃO DO REAL OU TOTALIDADE CONCRETA: O QUE DIZEM OS DADOS SOBRE A PRÁTICA PEDAGÓGICA DE DOCENTES DA SOCIOLOGIA DA ESCOLA BÁSICA?

Tatiana Bukowitz

explicitados pelas narrativas dos docentes entrevistados são analisados segundo o materialismo histórico-dialético. As informações fornecidas permitem que compreendamos a dupla inter-relação, muitas vezes perversa e danosa, existente entre as circunstâncias pedagógicas do cotidiano profissional escolar e a estrutura das suas rotinas de vida pessoal. A leitura dos dados fornecidos pelas entrevistas fundamenta-se na perspectiva teórico-metodológica de Karel Kosik e nos conceitos de totalidade complexa e pseudoconcreticidade, por ele adotados na obra Dialética do Concreto (1976). Complementarmente, o conceito de onilateralidade, empregado pelo estudioso Mario Alighiero Manacorda orienta-nos que o fenômeno estudado seja observado dentro da perspectiva marxista, trazendo à tona uma compreensão do ser humano de modo integral e dinâmico, em todas as esferas da vida, e não somente no plano profissional e/ou econômico. O resultado da pesquisa indica, de um lado, contradições entre o potencial crítico e subversivo dessa disciplina escolar bem como as motivações educacionais desses docentes e, de outro, 0 esvaziamento da prática escolar, a corrosão da vida privada, enfraquecimento da saúde, o desgaste físico e emocional desses profissionais, que, ainda assim, compreendem suas práticas pedagógicas como espaço privilegiado para a formação democratizadora, politizada e pluralista dos estudantes do ensino médio.

Palavras-chave: Ensino de Sociologia. Precarização do Trabalho Docente. Educação Básica. Metodologia de Pesquisa. Políticas Públicas Educacionais no Brasil.

Perguntas de um trabalhador que lê

[...] Quem construiu Tebas, a cidade das sete portas?

Nos livros estão nomes de reis; os reis carregam pedras?

[...] A cada página uma vitória. Quem preparava os banquetes comemorativos?

A cada dez anos um grande homem. Quem pagava as despesas?[...]

Tantas histórias.

Tantas questões.

Bertold Brecht ${ }^{3}$ (1976, p. 656.)

\footnotetext{
${ }^{3}$ O poema de Brecht demarca o posicionamento adotado na investigação e define elementos-chave das reflexões que propomos neste texto. Nesta poesia, o trabalhador é indicado como sujeito da História, ator das vitórias, construtor dos monumentos. As perguntas levantadas pela poesia conduzem-nos ao entendimento de que o trabalhador é responsável e colaborador relevante na
} 
Tatiana Bukowitz

\section{APRESENTAÇÃO DA INVESTIGAÇÃO: DEFININDO QUESTÕES}

A poesia Perguntas de um trabalhador que lê orienta o olhar para fatos que não são comumente contemplados na historiografia, embora estejam presentes na base material das sociedades e sejam definidores da própria organização social. Quando se estuda a eficácia dos sistemas educacionais, é muito comum desconsiderar-se as condições de trabalho nas quais se encontram os profissionais de educação. Por mais paradoxal que possa parecer, são frequentes as pesquisas que visam avaliar a pertinência de aspectos da educação sem considerar de perto os educadores a ela diretamente vinculados.

Ao buscarmos compreender melhor a implementação da sociologia como conteúdo curricular obrigatório nos currículos escolares desde 2008, entendemos, portanto, que seria essencial nos aproximarmos daqueles profissionais que efetivamente implementariam tal política pública (Lei 11.684/2008). Para tanto, três questões foram norteadoras de nosso processo investigativo:

1. Como se caracterizam a realidade pedagógica e a estrutura de trabalho profissional de docentes de sociologia/ciências sociais do ensino médio?

2. Qual o alcance das ações pedagógicas desses docentes diante das condições objetivas e subjetivas que circunscrevem o cotidiano de suas práticas educacionais?

3. Qual a interferência dessa estrutura de trabalho nas demais esferas da vida dessas pessoas que assumem a docência de sociologia na escola básica como profissão?

construção da história, seus principais fatos e de seus monumentos. As questões postas por Brecht também demonstram que os atos dos operários não costumam ser publicamente reconhecidos. Os feitos dos trabalhadores não costumam ser interpretados como oriundos da ação operária, mas sim como resultado da ação de reis. Essa poesia de Brecht não é uma abstração retórica. Ela categoriza a materialidade cotidiana de um contingente social transversalmente presente na trajetória humana, mas que é sistematicamente invisibilizado. São invisibilizados tanto os efetivos sujeitos da história bem como as suas condições de existência. Os trechos selecionados do poema Perguntas de um trabalhador que lê (Fragen eines lesenden Arbeiters) encontram-se em Gesammelte Gedichte (Poesia Completa), de Bertold BRECHT (1976). Aqui, empregamos a tradução de Leandro Konder, disponível em A poesia de Brecht e a História (s./d.). 


\section{INTER-LEGERE}

MISTIFICAÇÃO DO REAL OU TOTALIDADE CONCRETA: O QUE DIZEM OS DADOS SOBRE A PRÁTICA PEDAGÓGICA DE DOCENTES DA SOCIOLOGIA DA ESCOLA BÁSICA?

Tatiana Bukowitz

Com essas questões em mente, levamos a cabo a pesquisa de doutoramento que culminou na a tese Sociologia como (in)disciplina escolar: desafios da prática docente (defendida em junho de 2015 no PPFH - UERJ, Programa de PósGraduação de Políticas Públicas e Formação Humana da Universidade do Estado do Rio de Janeiro, sob orientação do Prof. Dr. Pablo Gentili). Buscando uma compreensão mais apurada sobre as condições de trabalho e de vida nas quais se encontram os docentes de sociologia, elaboramos um detalhado questionário composto de 61 questões. Por meio dessa ferramenta de pesquisa, captamos dados sobre quatro aspectos centrais:

A. Perfil da identidade individual e familiar dos(as) entrevistados(as);

B. Perfil da escala de trabalho profissional escolar dos(as) entrevistados(as);

C. Perfil das características de trabalho profissional escolar dos(as) entrevistados(as) e seus impactos na saúde e rotina do(a) docente;

D: Perfil das práticas pedagógicas empregadas no trabalho profissional escolar do(as) entrevistados(as) e seus impactos no processo de aprendizado dos estudantes.

Os dados sistematizados de modo mais detalhado podem ser encontrados no Capítulo 4 da tese de doutorado acima referida. Para essa ocasião, apresentamos somente uma síntese analítica dos dados dessa pesquisa de campo realizada em duas etapas. Na primeira, utilizou-se o questionário semiestruturado completo (com um total de 61 questões, mesclando questões objetivas com questões abertas), aplicado presencialmente a 10 docentes do Rio de Janeiro. A segunda etapa foi realizada com outros 10 docentes (6 do Rio de Janeiro e 4 de outros estados), empregando questionário semiestruturado, também mesclando questões objetivas com questões abertas, porém com um número reduzido de perguntas. Os integrantes desse segundo grupo de entrevistados forneceram cópias dos contracheques de suas atividades como profissionais docentes de sociologia, atestando de modo oficial os dados referentes aos salários por eles declarados. 


\section{INTER-LEGERE}

MISTIFICAÇÃO DO REAL OU TOTALIDADE CONCRETA: O QUE DIZEM OS DADOS

SOBRE A PRÁTICA PEDAGÓGICA DE DOCENTES DA SOCIOLOGIA DA ESCOLA

BÁSICA?

Tatiana Bukowitz

As perguntas presentes nos questionários eram bastante invasivas e as respostas fornecidas pelos entrevistados nos fazem pensar sobre os dados que caracterizam traços de uma realidade vil. Nossas perguntas não podiam ser delicadas e as respostas caracterizavam tristeza, surpresa e desconforto quando forneciam as informações ${ }^{4}$. Não tratávamos de temas divertidos. A investigação não versou sobre os principais destinos de férias dos proprietários de empresas de educação do Rio de Janeiro. Seu objetivo era traçar um perfil qualitativo e tão profundo quanto possível sobre vinte trabalhadores, profissionais docentes de sociologia. As questões se tornavam mais desconfortáveis à medida que fossem mais desconfortáveis os dados de realidade fornecidos pelos entrevistados. Qual salário recebido pelas tarefas que realiza? Você é responsável por quantos estudantes? Quantas turmas isso representa? Como se sente após a jornada de trabalho? Que efeitos essa modalidade de trabalho traz a seu corpo? O que costuma realizar no fim do dia trabalhado? E no período do fim de semana? Por quanto tempo pretende continuar nesse ofício docente?

Poderíamos obter respostas alegres e confortantes, se estivéssemos em outro contexto, norteados por princípios diferentes daqueles que norteiam o atual panorama de neoliberalismo econômico implementado no Brasil. Contudo, o quadro que se formou após a realização de dez entrevistas iniciais, bem como das dez entrevistas complementares (ver síntese nos quadros em anexo), apresentam circunstância sintomática de desgaste físico e mental associado a essa atividade profissional.

\section{CONSTITUIÇÃO DA TOTALIDADE CONCRETA: MÉTODO DE CONSTITUIÇÃO DE DADOS}

\footnotetext{
${ }^{4}$ Ao levantarmos dados sobre pesquisas realizadas com trabalhadores, visando levantar dados sobre suas condições gerais de existência, encontramos na obra, $A$ enquete operária, de Karl Marx ${ }^{4}$, grande afinidade com a estrutura básica da pesquisa aqui apresentada, especialmente pelo fato de ambas visarem compreender a estrutura cotidiana dos trabalhadores, em sua totalidade, e pelo fato de gerarem, nos entrevistados, tanto o desconforto como a consciência sobre uma série de fatores que acometem suas vidas devido às consequências do regime de trabalho a que estão submetidos seus corpos, mentes e estado psíquico.
} 


\section{INTER-LEGERE}

MISTIFICAÇÃO DO REAL OU TOTALIDADE CONCRETA: O QUE DIZEM OS DADOS SOBRE A PRÁTICA PEDAGÓGICA DE DOCENTES DA SOCIOLOGIA DA ESCOLA BÁSICA?

Tatiana Bukowitz

Os depoimentos advindos das dez entrevistas presenciais (apresentadas a seguir nos dados do Quadro 1) com duração média de três horas caracterizam o conjunto desses trabalhadores enquanto seres humanos integrais, indicando de que modo as diferentes esferas de suas vidas se inter-relacionam. O segundo grupo de dez docentes entrevistados foram contatados por correio eletrônico, meio pelo qual forneceram seus contracheques de trabalho (tais dados estão sintetizados a seguir no Quadro 2). Assim, trazemos aqui uma síntese dos dados obtidos, dando voz à realidade de um segmento de educadores que costuma ser duplamente emudecido - tanto pelo desgaste vocal proporcionado pela sua prática pedagógica, assim como pelas invisibilizadas condições de trabalho em que se encontram. Definidas por elevada precarização, as circunstâncias de trabalho específicas dos professores de sociologia (bem como das demais classes de educadores da escola básica) não são reconhecidas pelas políticas públicas educacionais do país. Retirar o véu que cobre tais realidades caracterizadas por precarização e adoecimento, fazer romper a invisibilidade e tornar evidentes os variados processos de destituição da dignidade do exercício educacional foi, portanto, o objetivo central de todo o processo investigativo. Trata-se de uma pesquisa politicamente engajada, sem a presunção das metodologias supostamente dotadas de neutralidade científica. Adotamos o materialismo histórico-dialético como base epistêmica, e, seguindo a perspectiva conceitual definida por Karel Kosik em sua obra Dialética do Concreto (1976), reconhecemos a necessidade de constituirmos nosso objeto de estudo enquanto totalidade concreta e não como pseudoconcreticidade.

Em sua obra Dialética do Concreto (1976), Kosik procura explicitar e distinguir o que é realidade concreta e o que é pseudoconcreticidade. Segundo a perspectiva teórica de Kosik, a pseudoconcreticidade é uma estrutura de representação da realidade fundamentada no senso comum, apresenta a realidade de modo limitado e os fenômenos como sendo dotados de uma pretensa independência (como formas reificadas e fetichizadas do mundo objetivo). A pseudoconcreticidade é responsável pelo ocultamento do mundo real, apresenta um movimento autônomo das estruturas sociais e, dessa forma, o sujeito desaparece. Segundo Kosik, a pseudoconcreticidade há de ser destruída pelo pensamento dialético (em oposição 


\section{INTER-LEGERE}

MISTIFICAÇÃO DO REAL OU TOTALIDADE CONCRETA: O QUE DIZEM OS DADOS SOBRE A PRÁTICA PEDAGÓGICA DE DOCENTES DA SOCIOLOGIA DA ESCOLA BÁSICA?

Tatiana Bukowitz

ao conhecimento positivista). Ou seja, a dialética é concebida como um método para conhecimento da autêntica objetividade da realidade, e para que isso seja possível, é necessário conhecer o caráter histórico do fenômeno, reconhecer a ação de seus sujeitos e reconhecer cada elemento/fenômeno como um aspecto de uma totalidade mais ampla.

Segundo a perspectiva dialética adotada por Kosik, é possível e necessário reconhecer a unidade intrínseca entre produção e produto; sujeito e objeto; gênese e estrutura. Este é o mundo real, em sua totalidade concreta: o real é um PROCESSO (não é um dado da natureza nem um dato "em si") em que se opera a humanização dos seres humanos, é o espaço da realização da verdade, verdade que não está pronta, mas que está sendo construída por uma miríade de sujeitos históricos. É para acessar fenômenos dinâmicos e compreendermos a dialeticidade do mundo real que Kosik adota o conceito de totalidade concreta.

A realidade concreta ou totalidade concreta é aquilo que efetivamente relaciona-se com a essência do fenômeno, e uma de suas características é sua contraditoriedade.

A compreensão da realidade concreta foge à percepção imediata, é dotada de inúmeras facetas (as quais, em sua totalidade, são incognoscíveis). Contudo, ao reconhecer na totalidade concreta a unidade entre produção e produto, sujeito e objeto, gênese e estrutura, Kosik encontra na realidade concreta o espaço para a ação e intervenção humanas: nesse campo encontra-se a práxis revolucionária da humanidade.

Complementarmente, o conceito de omnilateralidade, empregado pelo estudioso Mario Alighiero Manacorda em sua obra Marx e a pedagogia moderna (1991), orienta-nos que o fenômeno estudado (realidade de vida de docentes de sociologia) seja analisado dentro da perspectiva marxista, trazendo à tona uma compreensão do ser humano de modo integral e dinâmico, em todas as esferas da vida, e não somente no plano profissional e/ou econômico.

Efetivamente, ao fim das entrevistas obtivemos resultados que indicam contradições entre o potencial crítico e subversivo dessa disciplina escolar bem como as motivações educacionais desses docentes, de um lado; e de outro, o 


\section{INTER-LEGERE}

MISTIFICAÇÃO DO REAL OU TOTALIDADE CONCRETA: O QUE DIZEM OS DADOS SOBRE A PRÁTICA PEDAGÓGICA DE DOCENTES DA SOCIOLOGIA DA ESCOLA BÁSICA?

Tatiana Bukowitz

esvaziamento da prática escolar, a corrosão da vida privada ${ }^{5}$, enfraquecimento da saúde, o desgaste físico e emocional desses profissionais, que, ainda assim, compreendem suas práticas pedagógicas como espaço privilegiado para a formação democratizadora, politizada e pluralista dos estudantes do ensino médio. Ou seja, as informações fornecidas permitem que compreendamos a dupla inter-relação, muitas vezes perversa e danosa, existente entre as circunstâncias pedagógicas do cotidiano profissional escolar e a estrutura das suas rotinas de vida pessoal.

\section{SEM MISTIFICAR O REAL: SUJEITOS E ASPECTOS DO FENÔMENO SENDO EXPLICITADOS}

Organizando os dados mais objetivos e apresentando as condições materiais de trabalho sobre cada um dos dois grupos de entrevistados, sintetizamos os dados tais quais dispostos, a seguir, nos Quadro 1 (Síntese de dados objetivos sobre os docentes entrevistados) e Quadro 2 (Síntese de dados sobre a composição salarial e quantitativo de turmas de dez docentes/dez escolas - levantamento complementar por correio eletrônico).

Comparando os dois grupos de docentes entrevistados, respectivamente, encontramos os seguintes dados: média etária 32,6 e 34,3 anos; média de anos lecionados 5 e 6,9 anos de trabalho; média de turmas lecionadas 13,7 e 9,7 turmas; média salarial mensal entre os entrevistados, considerando apenas a fonte de renda advinda de trabalho docente $\mathrm{R} \$ 2.668,98$ (vide Quadro 1) e advinda de principal fonte de remuneração com a docência de sociologia na escola $R \$ 1.918,43$ (vide Quadro 2). Ou seja, os dois grupos amostrais, compostos por docentes diferentes, indicam dados semelhantes quanto à idade, tempo de docência, quantitativo de turmas e renda salarial.

\section{Quadro 1 - Síntese de dados objetivos sobre os docentes entrevistados}

\footnotetext{
${ }^{5}$ Tal como caracterizada por Richard Sennet em A Corrosão do Caráter: consequências pessoais do trabalho no novo capitalismo (1999).
} 
INTER-LEGERE

MISTIFICAÇÃO DO REAL OU TOTALIDADE CONCRETA: O QUE DIZEM OS DADOS SOBRE A PRÁTICA PEDAGÓGICA DE DOCENTES DA SOCIOLOGIA DA ESCOLA BÁSICA?

Tatiana Bukowitz

\begin{tabular}{|c|c|c|c|c|c|}
\hline $\begin{array}{c}\text { Homens } \\
\text { entrevistados } \\
5\end{array}$ & $\begin{array}{c}\text { Mulheres } \\
\text { entrevistadas } \\
5\end{array}$ & \multicolumn{2}{|c|}{$\begin{array}{c}\text { Total de escolas } \\
\text { abordadas } \\
\downarrow \\
22 \text { escolas }\end{array}$} & \multirow{2}{*}{$\begin{array}{c}\text { Média de anos } \\
\text { lecionados } \\
\text { por esses } \\
\text { profissionais } \\
\text { (até 2014) } \\
\downarrow \\
5 \text { anos }\end{array}$} & \multirow{2}{*}{$\begin{array}{c}\text { Média de } \\
\text { turmas } \\
\text { lecionadas } \\
\text { pelos } \\
\text { docentes } \\
\text { em } 2014 \\
\downarrow \\
13,7 \text { turmas }\end{array}$} \\
\hline $\begin{array}{c}\text { Média de idade } \\
\text { entre docentes } \\
\text { homens } \\
\text { entrevistados } \\
\downarrow \\
\begin{array}{c}\downarrow \\
30,6 \text { anos }\end{array}\end{array}$ & $\begin{array}{c}\text { Média de } \\
\text { idade entre } \\
\text { docentes } \\
\text { mulheres } \\
\text { entrevistadas } \\
\Downarrow \\
34,6 \text { anos }\end{array}$ & \multirow{2}{*}{$\begin{array}{c}\text { Total de } \\
\text { escolas } \\
\text { privadas } \\
\text { abordadas } \\
\downarrow \\
\qquad \text { escolas }\end{array}$} & \multirow{2}{*}{$\begin{array}{c}\text { Total de } \\
\text { escolas } \\
\text { públicas } \\
\text { abordadas } \\
\qquad \\
13 \text { escolas }\end{array}$} & & \\
\hline \multicolumn{2}{|c|}{$\begin{array}{l}\text { Média etária do } \\
\text { conjunto de docentes: }\end{array}$} & & & $\begin{array}{c}\text { Observação: } \\
\text { em geral } \\
\text { começaram a } \\
\text { lecionar um } \\
\text { ano após a } \\
\text { implementação } \\
\text { da } \\
\text { obrigatoriedade } \\
\text { da sociologia } \\
\text { como disciplina } \\
\text { escolar. }\end{array}$ & $\begin{array}{l}\text { Observação: } \\
\text { metade dos } \\
\text { entrevistados } \\
\text { possuía } \\
\text { regência de } \\
16 \text { a } 23 \\
\text { turmas } \\
\text { em } 2014 .\end{array}$ \\
\hline
\end{tabular}

Fonte: Dados coletados das entrevistas presenciais realizadas na pesquisa de campo.

Vale observar que a despeito da semelhança nos dados de renda, no grupo de docentes que compõe a segunda etapa de entrevistas, cada um deles apresentou APENAS UMA de suas fontes de renda (uma vez que, nesse caso, os dez entrevistados, cada um deles, lecionava em apenas UMA escola). Na segunda etapa, levantamos dados somente sobre a renda salarial oriunda da docência (na primeira etapa da pesquisa, levantamos dados sobre outras fontes de renda, mas não utilizamos esse dado na construção do Quadro 1 nem os requisitamos aos informantes da segunda etapa da pesquisa). Ou seja, diferente do Quadro 1 (composto por dados de docentes que lecionavam em mais de uma escola), a renda advinda da docência (aqui nesse Quadro 2 é oriunda de dados de DEZ escolas, uma de cada docente entrevistado (referente ao caso do levantamento complementar). 


\section{INTER-LEGERE}

MISTIFICAÇÃO DO REAL OU TOTALIDADE CONCRETA: O QUE DIZEM OS DADOS SOBRE A PRÁTICA PEDAGÓGICA DE DOCENTES DA SOCIOLOGIA DA ESCOLA BÁSICA?

Tatiana Bukowitz

Por esse motivo, a média de renda e o quantitativo de turmas lecionadas desse segundo grupo (Quadro 2) são um pouco mais baixos em relação ao Quadro 1.

Quadro 2 - Síntese de dados sobre a composição salarial e quantitativo de turmas de dez docentes/dez escolas (levantamento complementar por correio eletrônico)

\begin{tabular}{|c|c|c|c|}
\hline $\begin{array}{c}\text { Média de idade } \\
\text { dos docentes } \\
\downarrow \\
\text { 34,3 anos }\end{array}$ & $\begin{array}{c}\text { Média de } \\
\text { anos lecionados } \\
\text { na escola básica } \\
\downarrow \\
6,9 \text { anos }\end{array}$ & $\begin{array}{c}\text { Média de salário } \\
\text { mensal } \\
\text { (segundo } \\
\text { contracheques } \\
\text { fornecidos) } \\
\downarrow \\
\mathbf{R} \$ 1.918,43 \text {. }\end{array}$ & $\begin{array}{c}\text { Média de turmas } \\
\text { lecionadas } \\
\downarrow \\
\mathbf{9 , 7} \text { turmas }\end{array}$ \\
\hline \multicolumn{4}{|c|}{ Observação: } \\
\hline \multicolumn{4}{|c|}{$\begin{array}{l}\text { Na segunda etapa de entrevistas, levantamos dados de dez docentes, cada um deles } \\
\text { apresentou uma fonte de renda com o trabalho de docência de sociologia, pois somente } \\
\text { lecionava em uma escola. }\end{array}$} \\
\hline
\end{tabular}

Fonte: Dados coletados das entrevistas presenciais realizadas na pesquisa de campo.

O exame dos dados coletados com as dez entrevistas presenciais iniciais foi trabalhoso devido à quantidade e variedade de aspectos abordados. Sintetizamos a seguir dados trazidos por esse conjunto de depoimentos, e apresentamo-los em seis subitens temáticos, indicados em negrito, tal como relatamos a seguir.

1. Sobre as condições materiais de trabalho dos professores de sociologia, principais mediadores do processo cognitivo escolar na implementação da política pública em questão (Lei 11.684 de 2008), constatamos que os dez docentes são empregados em 12 escolas públicas estaduais, 01 escola pública federal, 9 escolas privadas (4 de elite e 5 de classe média ${ }^{6}$ ), ou seja, trabalham em 22 unidades escolares diferentes. Por meio dessa amostra, pudemos levantar dados de unidades escolares em 20 diferentes regiões da metrópole do Rio de Janeiro, contemplando áreas economicamente mais privilegiadas e outras bastante precarizadas. Nesse

\footnotetext{
"A caracterização como "escola privada de elite" ou de "classe média" foi dada pelos próprios docentes, e para isso empregaram o valor da mensalidade para definir a classificação. Como escolas de elite econômica, consideravam aquelas com mensalidades superiores a $R \$ 2.000,00$ por estudante, e como escolas de classe média mensalidades de até $\mathrm{R} \$ 1.000,00$ por estudante. Curiosamente, essa classificação foi equânime entre os que lecionam em escolas privadas.
} 


\section{INTER-LEGERE}

MISTIFICAÇÃO DO REAL OU TOTALIDADE CONCRETA: O QUE DIZEM OS DADOS SOBRE A PRÁTICA PEDAGÓGICA DE DOCENTES DA SOCIOLOGIA DA ESCOLA BÁSICA?

Tatiana Bukowitz

sentido, destacou-se o longo deslocamento que alguns docentes (os que lecionam em mais de uma unidade escolar) necessitam realizar por lecionarem em regiões bem distantes no mesmo dia.

Entre as escolas privadas cujas informações tivemos acesso, é comum que ofereçam apenas um único tempo de aula para cada uma das séries. Há a exceção de uma das escolas privadas de elite, a qual oferece dois tempos de sociologia/ciências sociais para todas as três séries do ensino médio. Contudo, as escolas privadas tendem a oferecer menos tempos de aula de sociologia/ciências sociais para o ensino médio que as escolas públicas do Estado, uma vez que nestas ainda resguardam-se dois tempos somente para as turmas de $3^{\circ}$ ano. A excepcionalidade entre as escolas públicas é a unidade federal de ensino a que tivemos acesso, que oferece dois tempos de aulas semanais para todas as séries.

Sobre o quantitativo de estudantes por turma, nota-se que é comum uma variação entre o quantitativo de estudantes na pauta e o quantitativo dos que frequentam as aulas. Nas escolas públicas do Estado, oficialmente é comum o fato de as pautas conterem entre 30 e 50 estudantes, o que indica que, para o serviço público de educação, esse é considerado um quantitativo legítimo, uma vez que é praticado oficialmente. A média de turmas sob responsabilidade de cada docente é de 13,7. Considerando como 30 a média de estudantes que frequentam as turmas, e de 13,7 o quantitativo médio de turmas por docente, chegamos ao dado de que cada docente tem, sob sua responsabilidade educacional, cerca de 411 discentes.

A média salarial mensal entre os entrevistados do primeiro grupo, considerando apenas a fonte de renda advinda de trabalho docente, é de $R \$$ 2.668,98, gerando uma média de hora, de $R \$ 28,28$. O total de renda MENSAL agregada pelo trabalho desses dez professores, que juntos lecionam em 22 escolas, para um total de 145 turmas, é $R \$ 26.689,83$. Quando se adicionam outras fontes de renda diferentes da docência à renda pela docência, a renda total entre esses docentes salta para $R \$ 30.089,00$, compondo uma média entre eles de $R \$ 3.008,98$, acrescendo $\mathrm{R} \$ 340,00$ para cada um, em média. Dentre os dez entrevistados, apenas dois deles possuíam fonte de renda complementar, sendo uma delas a bolsa 


\section{INTER-LEGERE}

MISTIFICAÇÃO DO REAL OU TOTALIDADE CONCRETA: O QUE DIZEM OS DADOS SOBRE A PRÁTICA PEDAGÓGICA DE DOCENTES DA SOCIOLOGIA DA ESCOLA BÁSICA?

Tatiana Bukowitz

de doutorado e a outra um trabalho temporário na Secretaria de Cultura de Niterói $(\mathrm{RJ})$.

Ao avaliarem a renda que obtêm a partir da docência, sobressai a percepção de que o salário é baixo para uma quantidade elevada e exaustiva de trabalho, o que dificulta o acesso à formação continuada. A disponibilidade de bolsas de estudo para docentes é diferenciada em cada programa de pós-graduação, criando dificuldades para que todos os docentes que assim o desejem avancem em suas formações complementares.

Ainda sobre as condições de trabalho dos docentes, majoritariamente, emprega-se o transporte coletivo público. O tempo médio de deslocamento em cada dia trabalhado é de 1 h42min, tempo investido na atividade de trabalho, mas que não é tempo pago (em geral, sequer o valor total das passagens é pago, quiçá o valor investido no transporte diário, o que, ao nosso ver, caracteriza mais um item na extração de mais-valia do trabalhador).

Nesse conjunto de professores, cuja média etária é 32,6 anos, oito não possuíam filhos e dois possuíam (esses dois eram professores homens). Apenas uma pessoa morava sozinha, as demais dividem moradia. Somente os dois homens com filhos usam a renda mensal para pagar despesas de demais integrantes da família. Os 8 demais entrevistados não usam a renda mensal para ajudar em despesas da família, empregam-na apenas para gastos pessoais. Só uma pessoa paga seus gastos pessoais autonomamente, e nove entrevistados necessitam de ajuda financeira para cobrir despesas básicas de moradia, alimentação e saúde. Entre os dez docentes, um entrevistado não possuía plano de saúde privado. Mencionou-se nas entrevistas a preocupação com a saúde, a necessidade de adotar planos de saúde privados e o descrédito com os serviços públicos de saúde disponíveis. Entre os nove que possuem plano de saúde privado, cinco eram pagos integralmente pelos docentes, e quatro possuíam ajuda para pagá-lo. Sequer as despesas com saúde privada pode ser contemplada autonomamente por todos. Apesar da média etária de 32,6 anos, idade adulta, nenhum entrevistado possui imóvel próprio que tenha sido pago pelo resultado de seu trabalho. Prevalece a residência na casa dos genitores. A autonomia financeira não é possibilitada pelos 
Tatiana Bukowitz

salários dos docentes. A única docente que mora sozinha, por meio de aluguel, possui esse contrato imobiliário no nome do pai, pois o nome dessa docente consta no SPC/SERASA (sistema de aferição de débitos ativos).

2. Sobre 0 impacto das circunstâncias objetivas e rotina de trabalho nas condições de saúde física e mental dos docentes entrevistados, notamos nitidamente a presença de elementos deletérios resultantes da falta de regulamentação específica sobre essa política pública escolar. Majoritariamente, os entrevistados iniciaram a docência após a implementação da Lei nacional 11.684/2008. O tempo médio de docência entre esses profissionais é de 5,5 anos. Inicialmente, ao responderem pergunta genérica sobre sua saúde, oito dos dez entrevistados responderam que não apresentaram problemas de saúde decorrentes do exercício da função docente. Contudo, ao serem questionados em pergunta aberta sobre o mesmo tema, começaram a relatar sintomas frequentes de desgaste da voz: inflamações na faringe; rinite; aumento exacerbado do consumo de alimentos e álcool associados a ganho elevado de peso; enxaqueca; cansaço extremo; insônia; estresse e quadro depressivo. Ao falarem dos seus sintomas, parte deles tomou consciência da associação entre a fragilidade na saúde ao ofício de professor/a. É comum o relato de cansaço mental e psíquico: embora alguns ainda tenham voz para falar, ao chegarem ao lar não o desejam fazê-lo devido ao cansaço extremo. Necessitam de recolher-se e de silenciar pelo resto do dia.

O sono não é caracterizado como um descanso reparador e saudável na rotina de parte dos entrevistados. Relatam o sono em quantidade insuficiente para o descanso físico durante a semana, relacionado a elevado estresse e sensação de estafa e ansiedade. Ocorre o uso de álcool e de medicamentos controlados para lidar com estresse ou outros problemas de ordem emocional. Reconhecem que, diante do quadro apresentado, seria necessário acompanhamento terapêutico regular, mas não o fazem por impossibilidade financeira. Mesmo tendo entrevistado docentes que lecionam há cerca de 5,5 anos apenas, já encontramos significativos sinais de desgaste físico e psíquico. Em geral, o tempo após a atividade de trabalho docente nas escolas é caracterizado como de pouco rendimento para estudos aprofundados, sendo utilizado, para descanso, atividades de lazer ou atividade 
Tatiana Bukowitz

física. Nos depoimentos, os docentes reconhecem a necessidade de fazerem atividades físicas, contudo apenas metade consegue efetivar uma rotina de praticar exercício.

Ao perguntarmos sobre o uso do tempo nos fins de semana (sábados e domingos), obtivemos, em todas as respostas, alguma menção ao trabalho: ora para dizer que se trabalha nos fins de semana, ora para dizer que se recusa a trabalhar, ora para dizer que evita trabalhar, mas não consegue evitar o trabalho no fim de semana. Mencionou-se repetitivamente a resistência a se trabalhar no fim de semana. As atividades da profissão docente, contudo, envolvem muitas outras tarefas para além do que é executado em sala de aula, portanto há um acúmulo de trabalho invisibilizado e não pago, invadindo, costumeiramente, os momentos que deveriam ser restritos para as atividades da vida pessoal. As atividades do trabalho docente transpassam as fronteiras ou destituem fronteiras entre o espaço da vida privada e aquele da vida profissional.

3. No intuito de identificar o papel atribuído à sociologia como disciplina regular na escola básica, verificamos que, na perspectiva dos entrevistados, a sociologia/ciências sociais pode agregar aos estudantes uma visão de mundo diferenciada sobre a realidade. Defendem a ampliação de tempos semanais de aula para todas as turmas, atestam que ela pode trazer aos estudantes um potencial crítico e analítico da sociedade em que vivem. Foram unânimes ao afirmarem que a neutralidade científica é uma impossibilidade, corroborando um dos princípios da sociologia crítica defendida por Florestan Fernandes.

Paradoxalmente, apesar de todo o quadro de precarização enfrentado por esses docentes em seu cotidiano escolar, 6 declaram desejar continuar na docência de sociologia no ensino médio por muito tempo e 4 afirmaram que desejam manterse nessa atividade por um tempo limitado. Não houve docente que informasse não desejar permanecer nesse ofício. A permanência nessa atividade profissional, a despeito de seus agouros, é compreendida como um modo de intervenção direta na sociedade, tendo em vista a colaboração em processos mais ampliados de transformação social e até mesmo como militância na educação. O gosto pela atividade docente foi nítido em todos os depoimentos. 


\section{INTER-LEGERE}

MISTIFICAÇÃO DO REAL OU TOTALIDADE CONCRETA: O QUE DIZEM OS DADOS

SOBRE A PRÁTICA PEDAGÓGICA DE DOCENTES DA SOCIOLOGIA DA ESCOLA

BÁSICA?

Tatiana Bukowitz

4. Ao analisarmos a formação acadêmico-profissional desses professores de sociologia e ao associar essa com a prática pedagógica por eles realizada, verificamos que todos possuem graduação em ciências sociais e também possuem, pelo menos, uma especialização na área de ciências sociais ou de ensino de sociologia, sendo nítido o interesse pelo aperfeiçoamento profissional, mas difícil de ser conciliado com o ofício docente.

5. A análise da prática pedagógica dos docentes de sociologia entrevistados trouxe-nos dados que relatam a presença de aulas expositivas e fazendo anotações de tópicos na lousa para os estudantes copiarem. Comentaram que é pouco o tempo em sala e que isso não possibilita diversificar atividades pedagógicas, embora tentem fazer uso de variadas ferramentas didáticas quando possível. Os livros didáticos são pouquíssimo utilizados com os estudantes: oito docentes citaram o livro didático como um dos elementos que nunca é empregado em sala de aula. Apesar de o recurso didático ser disponível em 13 escolas, e parcialmente disponível em outras duas, essa foi a ferramenta didática mais citada como aquela que nunca é usada em sala de aula. Diante desse fato, vale questionarmos, e aprofundarmos em pesquisa futura, qual é, então, a utilidade efetiva destinada aos livros didáticos de sociologia/ciências sociais, uma vez que, inclusive, o PNLD ${ }^{7}$ passa, desde 2009, a prever o ensino de sociologia e o fornecimento de livros dessa disciplina escolar.

Foi positivo verificar que o preparo de aulas é uma preocupação de todos os docentes entrevistados. Alguns informam que utilizam muito tempo para o preparo das aulas, estudando nos livros didáticos de ensino de sociologia/ciências sociais ou mesmo recorrendo aos trabalhos dos autores e pesquisadores das ciências sociais nos seus originais.

\section{Avaliando a inserção do ensino de sociologia nas escolas enquanto} política pública educacional nacional, por meio do conteúdo das entrevistas, efetivamente percebemos que sua efetivação material ocorre no espaço escolar por intermédio dos professores junto ao grande contingente de estudantes, o que

\footnotetext{
7 Detalhes sobre o histórico do PNLD (Programa Nacional do Livro Didático) e a ampliação gradual deste programa podem ser encontrados no site <http://www.fnde.gov.br/programas/livro-didatico/livrodidatico-historico >. Acesso em: 20/03/2017.
} 
MISTIFICAÇÃO DO REAL OU TOTALIDADE CONCRETA: O QUE DIZEM OS DADOS SOBRE A PRÁTICA PEDAGÓGICA DE DOCENTES DA SOCIOLOGIA DA ESCOLA

\section{BÁSICA?}

Tatiana Bukowitz

caracteriza uma política pública de duplo impacto (atingindo, nacionalmente, docentes e discentes). Contudo, essa não tem sido uma política educacional capaz de valorizar ou diminuir a precarização do trabalho dos educadores. Pelo contrário, vem à tona nos depoimentos a desvalorização da profissão docente e, em especial, a profissão de docente de sociologia. Ainda assim, cinco docentes apresentaram aspectos positivos da profissão quando dizem que se sentem desafiados, responsabilizados por realizar um projeto novo, com elementos originais para a educação.

Nos comentários complementares (última pergunta do questionário), destacam-se observações sobre o ambiente nocivo que constitui a escola em que lecionam e a necessidade de o ofício de docente de sociologia ser valorizado tanto economicamente como conteúdo cognitivo que exige formação específica dos profissionais de educação a ela direcionados.

Diante do entendimento dos elementos que constituem a vida desses docentes, percebemos o trabalho educacional como que em uma linha de montagem, em convergência com os princípios da pedagogia tecnicista. As consequências dessas práticas "pedagógicas" para o cotidiano educacional são apontadas com clareza por Saviani:

O magistério passou, então, a ser submetido a um pesado e sufocante ritual, com resultados visivelmente negativos. $\mathrm{Na}$ verdade, a pedagogia tecnicista, ao ensaiar transpor para a escola a forma de funcionamento do sistema fabril, perdeu de vista a especificidade da educação, ignorando que a articulação entre escola e processo produtivo se dá de modo indireto e por meio de complexas mediações. [...] Nessas condições, a pedagogia tecnicista acabou por contribuir para aumentar o caos no campo educativo, gerando tal nível de descontinuidade, de heterogeneidade e de fragmentação, que praticamente inviabiliza o trabalho pedagógico (SAVIANI, 2009, p. 13, grifos nossos).

É lamentável detectarmos que docentes animados e engajados em seus objetivos educacionais encontrem tamanhas limitações no campo educacional onde atuam. Diante desse cenário, retomamos a poesia de Brecht, e perguntamo-nos: que grande feito desejamos alcançar? Por maior que seja o esforço desses 


\section{INTER-LEGERE}

MISTIFICAÇÃO DO REAL OU TOTALIDADE CONCRETA: O QUE DIZEM OS DADOS SOBRE A PRÁTICA PEDAGÓGICA DE DOCENTES DA SOCIOLOGIA DA ESCOLA BÁSICA?

Tatiana Bukowitz

docentes, o movimento por eles realizado não é pleno. Está, em grande medida, limitado. Nesses relatos pudemos ver asas cortadas, engaioladas por sistemas e lógicas que alienam e limitam suas performances em seus campos de ação. Esperamos que o passar dos anos não os faça esquecerem-se de como é voar.

\section{REFERÊNCIAS}

BRASIL. PNLD - Programa Nacional do Livro Didático: histórico. Disponível em: <http://www.fnde.gov.br/programas/livro-didatico/livro-didatico-historico>. Acesso em: 20 mar. 2017.

BRECHT, Bertold. Perguntas de um trabalhador que lê. Tradução de Leandro Konder. A poesia de Brecht e a história. Instituto de Estudos Avançados da Universidade de São Paulo. 1976. Disponível em: $<$ http://www.iea.usp.br/publicacoes/textos/konderbrecht.pdf >. Acesso em: 01 jan. 2011.

FERNANDES, Florestan. Sociedade de classes e subdesenvolvimento. Rio de Janeiro: Zahar, 1972.

FERNANDES, Florestan. Capitalismo dependente e classes sociais na América Latina. Rio de Janeiro: Zahar, 1975.

FERNANDES, Florestan. A sociologia no Brasil: contribuição para o estudo de sua formação e desenvolvimento. Petrópolis: Vozes, 1977.

FERNANDES, Florestan. A natureza sociológica da sociologia. São Paulo: Ática, 1980.

FERNANDES, Florestan. O desafio educacional. São Paulo: Cortez; Autores Associados, 1989.

FERNANDES, Florestan. A sociologia como afirmação. In: IANNI, Octávio. Florestan Fernandes: sociologia crítica e militante. São Paulo: Expressão Popular, 2011. p. 173-217.

KOSIK, Karel. Dialética do Concreto. Rio de Janeiro: Paz e Terra, 1976, 1986.

MANACORDA, Mario Alighiero. Marx e a pedagogia moderna. São Paulo: Cortez; Autores Associados, 1991.

MARX, Karl. O questionário de 1880. In: THIOLLENT, Michel (Org.). Crítica metodológica, investigação social e enquete operária. São Paulo: Polis, 1982. p. 249-256. 


\section{INTER-LEGERE}

MISTIFICAÇÃO DO REAL OU TOTALIDADE CONCRETA: O QUE DIZEM OS DADOS SOBRE A PRÁTICA PEDAGÓGICA DE DOCENTES DA SOCIOLOGIA DA ESCOLA BÁSICA?

Tatiana Bukowitz

SAVIANI, Dermeval. Escola e democracia. 41. ed. Campinas: Autores Associados, 2009.

SAVIANI, Dermeval. Antecedentes, origem e desenvolvimento da pedagogia histórico-crítica. In: MARSIGLIA, Ana Carolina Galvão. (Org.). Pedagogia Históricocrítica: 30 anos. Campinas: Autores Associados, 2011. p. 197-225.

SAVIANI, Dermeval. Pedagogia histórico-crítica: primeiras aproximações. Campinas: Autores Associados, 2012a.

SAVIANI, Dermeval. Pedagogia no Brasil: história e teoria. Campinas: Autores Associados, 2012b.

SAVIANI, Dermeval. Aberturas para a história da educação: do debate teóricometodológico no campo da história ao debate sobre a construção do sistema nacional de educação no Brasil. Campinas: Autores Associados, 2013.

SENNETT, Richard. A Corrosão do caráter: consequências pessoais do trabalho no novo capitalismo. Tradução de Marcos Santarrita. Rio de Janeiro: Record, 1999. 